\title{
Interparietal Inguinal Hernia with Ectopic Testis - An Uncommon Surgical Emergency
}

\author{
Sunilkumar B. Alur ${ }^{1}$, Sangeetha Siva ${ }^{2}$ \\ ${ }^{1,2}$ Department of General Surgery, Acura Speciality Hospital, Bangalore, Karnataka, India.
}

\section{PRESENTATION OF CASE}

A 46-year-old gentleman presented to casualty with a reducible right groin swelling (Figure 1) present since childhood which had suddenly become painful and irreducible for the past 6 hours. He gives history of absent right testis since childhood. There's no history of vomiting, abdominal distension or obstipation. He had no surgeries in the past, no testicular disease or infertility problems. Physical examination revealed obstructed inguinal hernia with doubtful strangulation, absent right testis and normal appearing left testis. After evaluation, patient underwent emergency exploration of right inguinal hernia under general anaesthesia which revealed gangrenous small bowel, omentum in between external oblique aponeurosis and skin without a hernia sac (Figure 2) and; ectopic right testis in the superficial inguinal pouch (Figure 3). Segmental resection of gangrenous bowel with primary anastomosis and right orchidectomy performed through the same inguinal approach. Anatomical repair of posterior wall followed by approximation of external oblique aponeurosis was performed. Histopathology report showed gangrenous ileum with patchy necrosis; testis with tubular atrophy and hyalinisation, maturation arrest of spermatogonia and hyperplasia of interstitial Leydig cells. Post-operative recovery was uneventful.

\section{CLINICAL DIAGNOSIS}

Obstructed right inguinal hernia.

\section{DIFFERENTIAL DIAGNOSIS}

Vaginal hydrocele, encysted hydrocele of cord, spermatocele, femoral hernia, undescended testis in the inguinal canal, lipoma of the cord, saphena varix, femoral aneurysm.
Corresponding Author: Dr. Sunilkumar B. Alur,

Flat No. 228, B-3, Netravathi, National Games Village, Kormangala. Bangalore 560047, Karnataka, India.

E-mail: drsunilalur@gmail.com

DOI: 10.14260/jemds/2021/196

How to Cite This Article:

Alur SB, Siva S. Interparietal inguinal hernia with ectopic testis - an uncommon surgical emergency. J Evolution Med Dent Sci 2021;10(12):912-914, DOI: 10.14260/jemds/2021/196

Submission 06-11-2020,

Peer Review 26-01-2021,

Acceptance 02-02-2021,

Published 22-03-2021.

Copyright (C) 2021 Sunilkumar B. Alur et al. This is an open access article distributed under Creative Commons Attribution License [Attribution 4.0 International (CC BY 4.0)] 


\section{PATHOLOGICAL DISCUSSION}

Among the surgical emergencies encountered by surgeons, strangulated inguinal hernia is a common pathology worldwide causing intestinal obstruction in all ages. A inguinal hernia which lies in between the layers of abdominal wall muscles are a rare type of inguinal hernia called the interparietal inguinal hernias, and is usually associated with ectopic or incompletely descended testis. ${ }^{1,2}$ Interparietal inguinal hernias are divided into three subtypes namely, the preperitoneal (hernia sac lying in between peritoneum and transversalis fascia), the interstitial (hernia sac lying in between transversalis fascia and transverse abdominis, internal oblique or external oblique muscles), and the superficial (hernia sac lying in between external oblique and skin or within aponeuroses of the inguinal region). ${ }^{3,4}$ They account for $0.01-1.6 \%$ of all inguinal hernias of which, interstitial subtype comprised $60 \%$, while the other two subtypes occurred $29 \%$ each. ${ }^{5}$ The ipsilateral testis of patients with interparietal hernia usually lies at or just outside the external inguinal ring, where it blocks further descent of the hernia sac, thereby causing it to advance between the layers of the abdominal wall muscles. ${ }^{6}$ Approximately $75 \%$ of imperfectly descended testes are associated with inguinal hernia; a sufficient reason in itself for advising surgery. ${ }^{7}$ "Testicular descent occurs in two phases: a transabdominal phase and an inguinoscrotal phase. ${ }^{8}$ The first phase, the transabdominal phase ( 8 - 15 weeks of gestation) is controlled by enlargement of the gubernaculum and regression of the cranial ligament. Insulin-like hormone 3 is the primary regulator of the first phase, possibly assisted by müllerian inhibiting substance / antimüllerian hormone (MIS / AMH) and by regression of the cranial suspensory ligament induced by testosterone. The second phase $(25-35$ weeks of gestation), the inguinoscrotal phase, requires migration of the gubernaculum from the groin into the scrotum, and its migration is guided by calcitonin gene-related peptide released by the genitofemoral nerve. The inguinoscrotal phase of testicular descent is regulated by androgens and by calcitonin gene-related peptide release by the sensory nucleus of the genitofemoral nerve.2,9-11 Deflection in the regulatory mechanism may result in a variety of structural defects such as indirect inguinal hernia, hydrocele, undescended testis, interparietal hernia or Spigelian hernias. ${ }^{8}$ When there's closed vaginal process and intact internal ring, a preperitoneal type of interstitial inguinal hernia is to be expected whereas interstitial inguinal hernia is assumed to pass through the internal ring. 6 To propose, arrest in transabdominal phase is commonly associated with spigelian hernia and arrest in inguinoscrotal phase is associated with interparietal inguinal hernias. ${ }^{12}$ As a result of failure of the gubernaculums to migrate into the scrotum, the inguinal canal space was not well developed, ${ }^{13}$ and the hernia sac expanded between the external oblique aponeurosis and the internal oblique muscle as well as through the inguinal canal. (Figure 5)

\section{DISCUSSION OF MANAGEMENT}

Interparietal inguinal hernias pose a preoperative diagnostic challenge to surgeons. It can present as an unusual inguinal hernia or as acute abdomen. The pathophysiological knowledge of interparietal inguinal hernia associated with ectopic testis would guide to a correct preoperative diagnosis; thus, simplify the surgical approach in such emergency situations. Early elective surgery is recommended in cases of groin swellings with associated ipsilateral absent testis.
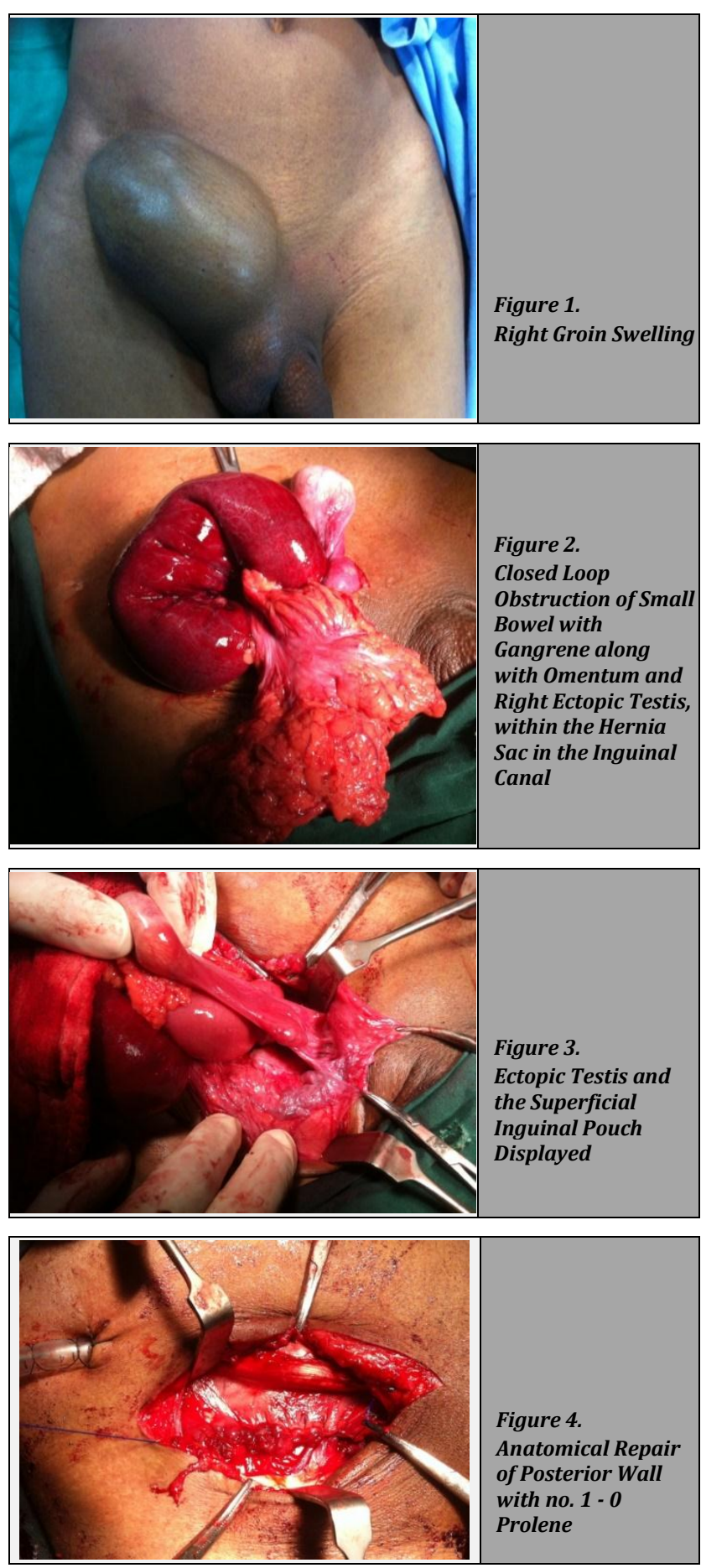

The numerals 1, 2, 3, 6, and 9 indicate the positions of the inferior epigastric vein, vas deferens, testicular vessels, hernia orice (deep inguinal ring), and superficial inguinal ring, respectively. The small letters a, b, c, d, e, e', f, g, h, i, j, and k indicate the positions of the testis, epididymis, gubernaculum, external oblique aponeurosis, internal oblique muscle, cremaster muscle, skin, transverses abdominis muscle, fascia transversalis, peritoneum, pubic bone, and scrotum, respectively. 


Figure 5.
Figures I-a and I-b are
Schematic Views of the
Pathogenetic Mechanism of
Typical Indirect Inguinal
Hernias. "The Patent
Processus Vaginalis Extends
in the Inguinoscrotal
Direction Through the
Inguinal Canal (I-a). The
Space of the Hernia Sac (the
Patent Processus Vaginalis)
was Expanded in the Same
Direction by the Abdominal
Pressure (I-b)
Figures II-a and II-b Show
Schematic Views of our
Hypothesized Pathogenetic
Mechanism of Interparietal
Hernia. The Gubernaculum
has Stopped at the
Abdominal Wall and Fixed
the Testis, Epididymis, and
Peritoneum (Patent
Processus Vaginalis) at the
Abdominal Wall, just
Beneath the External
Oblique Aponeurosis (II-a).
The Space of the Hernia Sac
(the Patent Processus
Vaginalis) has Expanded
Superiorly between the
External Oblique
Aponeurosis and the
Internal Oblique Muscle and
in an Inguinoscrotal
Direction Through the
Inguinal Canal (II-b)"13

\section{CONCLUSIONS}

Inguinal hernia lying in between layers of abdominal wall are a rare type of interparietal inguinal hernia in the inguinal region. Surgery at the earliest in such cases will reduce the incidence of complications and increase probability of salvaging the ectopic / undescended testis. Elective orchidectomy with hernioplasty should be considered in adults who have completed the family life.

\section{FINAL DIAGNOSIS}

Strangulated interparietal inguinal hernia with ipsilateral ectopic testis.

Financial or other competing interests: None.

Disclosure forms provided by the authors are available with the full text of this article at jemds.com.

\section{REFERENCES}

[1] Altman B. Interparietal Hernia. In: Nyhus L, Condon RE, eds. Hernia. $3^{\text {rd }}$ edn. Pennsylvania: Lippincott 1989: p. 380-7.

[2] Plataras C, Alexandrou I, Bourikis G, et al. An extremely rare case of indirect hernia type co-existing with testicular ectopia. Pan Afr Med J 2020;35:119.

[3] Zollinger RM Jr. Classification of ventral and groin hernias. In: Fitzgibbons RJ, Greenburg AG, eds. Nyhus \& Condon's Hernia. Philadelphia: Lippincott Williams \& Wilkins 2002: p. 71-9.

[4] Kumar A, Paswan SS, Paswan A, et al. Giant interparietal inguinal hernia with undescended testis-a rare case report. Int J Surg Case Rep 2018;42:4-6.

[5] Lower WE, Hicken NF. Interparietal hernias. Ann Surg 1931;94(6):1070-87.

[6] Koot VC, de Jong JR, Perre CI. The interparietal hernia: a rare variant of an inguinal hernia. Eur J Surg 1997;163(2):153-5.

[7] Bailey H. Mal-Descent of the testis and some of its problems. Postgrad Med J 1933;9(93):247-50.

[8] Tanyel FC. Obliteration of processus vaginalis: aberrations in the regulatory mechanism result in an inguinal hernia, hydrocele or undescended testis. Turk J Pediatr 2004;46 Suppl:18-27.

[9] Lie G, Hutson JM. The role of cremaster muscle in testicular descent in humans and animal models. Pediatr Surg Int 2011;27(12):1255-65.

[10] Hutson JM, Hasthorpe S. Abnormalities of testicular descent. Cell Tissue Res 2005;322(1):155-8.

[11] Hutson JM, Nation T, Balic A, et al. The role of the gubernaculum in the descent and undescent of the testis. Ther Adv Urol 2005;1(2):115-21.

[12] Hirabayashi T, Ueno S. Rare variant of inguinal hernia, interparietal hernia and ipsilateral abdominal ectopic testis, mimicking a spiegelian hernia. Case Report. Tokai J Exp Clin Med 2013;38(2):77-81.

[13] Biasutto SN, Repetto E, Aliendo MM, et al. Inguinal canal development: the muscular wall and the role of the gubernaculum. Clin Anat 2009;22(5):614-8. 